\title{
Precise Poverty Alleviation Problems and Countermeasures in Xinjiang Uygur Autonomous Region
}

\author{
Yang Yang, Aiping Zhang \\ College of Economics and Management, Tarim University, Xinjiang, 84300, China
}

Keywords: Precise poverty alleviation, Industrial structure, Poverty alleviation mechanism

Abstract: Xinjiang Uygur Autonomous region lies in the northwest of China, and its regional development is relatively backward due to the impact of climate and other environmental aspects, poverty has been an important factor restricting its economic development. In order to solve the poverty problem in Xinjiang effectively, we must fulfill the implement of precise poverty alleviation. This paper introduced the precise poverty alleviation work in Xinjiang Uygur Autonomous Region and mainly divided into six parts. The first part introduced the poverty alleviation background, the second part analyzed the exist problems in poverty alleviation work, the third part describes the importance to implement precise poverty alleviation, then summarizes the basic guiding ideas and principles on our current poverty alleviation work, next presents some countermeasures and suggestions and finally summarized the whole article. At the same time, the author hope that through this research the precise poverty alleviation work in Xinjiang Uygur Autonomous Region can be fulfill, and reducing the gap between rich and poor, accelerate the rapid development of western region.

\section{Introduction}

For the current poverty alleviation work in Xinjiang Uygur Autonomous Region, it is important to establish precise poverty alleviation mechanism, combining the poverty alleviation idea and action into the construction work, effectively reducing the gap between the rich and the poor in Xinjiang, promoting its rapid development. According to statistics, from 2001 to 2010, here has invested more than 15 million anti-poverty funds, benefiting approximately 2.9 million poor residents, and the per capita net income of poor local residents raised from 980 in 2001 to 3450 in 2010, showing that anti-poverty work is indeed helped the regional economic development. The anti-poverty work in new era advocates precise poverty alleviation which differs from extensive anti-poverty, it is mainly focusing on different poverty regions and population situation to using scientific and reasonable procedures to precise identify, helping and management on poverty objects. Precise poverty alleviation emphasized that supporting the one who is truly needed. "Precise poverty alleviation" concept is mainly originate from the guiding ideology of president Xi Jinping when he visits western Hunan in Nov. 2013: "seek truth from facts, take actions that suit local circumstance, classify and guidance, precise anti-poverty", then our country began to promote the rapid development of precise poverty alleviation. However, seen from the current anti-poverty work in Xinjiang Uygur Autonomous Region, there are still many problems needs to be solved.

\section{Some problems exist in the anti-poverty work in Xinjiang Uygur Autonomous Region}

\section{Lower utilization of anti-poverty funds}

According to statistics, in the period of 2001 to 2010, Xinjiang Uygur Autonomous Region 
carried out the anti-poverty and development plan toward more than 2200 poor villages, invested total funds 290 million. Except in the south Xinjiang like Sandizhou and others who actively analyzed the cause of poverty, identify the poverty objects and developed a number of effective anti-poverty strategies to ensure the proper utilization of funds, more than $80 \%$ anti-poverty funds is mainly used in production and construction and other infrastructure development, and only a few portion is used in science and technology investment or social security, existing lower utilization of anti-poverty funds situation, resulting in a number of poor individuals can't really get help.

\section{Lower benefit on industrial anti-poverty}

During the past 10 years, Xinjiang has carried out several particular anti-poverty strategies like "special industry economy" "leading enterprises supporting the poor", which has adjusted the regional industrial structure and transferred their finance sources. Although the industrial structure being more reasonable, comparing with developed areas, its economic benefits are still low, many regions still dependent on the weather phenomenon and affected by various factors. In short, the low economic benefit in industrial has been a major reason that limits the regional industrial development.

\section{Imperfect social security and education security}

Seen from the utilization of anti-poverty funds, $80 \%$ of the funds is devoted for the construction of infrastructure, few is used in social security, many problems like lack of health care ground and staff, few number of schools and transportation difficulties causing education problems in poor areas. It is mainly caused by the establish of the device security system of poverty areas is still incomplete, the initial establish of health care system made people spent more costs to see a doctor and imperfect education security system can't promote local economy development which intensified poverty. Therefore, the imperfect social security system is a major problem need to be solved.

\section{Analysis on the importance of precise poverty alleviation}

The so-called precise poverty alleviation refers focusing on different poverty regions and population situation to using scientific and reasonable procedures to precise identify, helping and management on poverty objects. Xinjiang Uygur Autonomous Region has always been the province of poverty in China, and its economic development is relatively backward, thus to carry out precise anti-poverty work here have an important practical significance.

First, solving the poverty situations is the reality requirement, to achieve a balanced development between poor areas in Xinjiang and developed areas, meanwhile, it promote the integration of poverty ethnic areas with other regions. Second, it helps local residents transfer their economic sources. Currently, the poverty of Xinjiang residents is caused by different factors and precise anti-poverty focusing on various aspects to solve the poverty problem effectively. Then, under the new situation, government needs to transfer its functions in response to the needs of population. It requires government to improve the infrastructure construction, solving the problems of food and clothing, to fulfill the problems of health, education, pension and other aspects, perfect the social security and education security to effectively solving various difficulties.

\section{Guiding ideology and basic principles on precise poverty alleviation}

\section{Guiding ideology of precise poverty alleviation in Xinjiang}

According to the central deployment on poverty alleviation and the requirements of "China Rural Poverty Alleviation and Development Program (2011-2020)”, with the guidance of the eighteenth 
national congress of the CPC spirit, and developing "poverty alleviation and development and national unity demonstration county" as the overall objective, we should continue adhere to the principle of "one region and three county" as the main battlefield, using the reform and innovation as the driving force, and construct "the trinity" anti-poverty pattern as the path to strive to eliminate institutional obstacles, pay attention to the outstanding problems that constraints local development to enhance their self-development capability, the equalization of basic public services and precise poverty alleviation to accelerate poor masses out of poverty and the pace of building a moderately prosperous society in poverty-stricken areas.

\section{Basic principles of precise poverty alleviation}

First, regarding development as body, the people's livelihood as the tasks, which means the main task of anti-poverty is to accelerate its development, insist on strengthening its basic public services and social security and other livelihood issues, and effectively protect people's living and developing.

Second, overall consideration and focus on tough points, namely regarding Xinjiang special poverty area as the main area of anti-poverty, integrate of all aspects of poverty alleviation resources, focus on improving its production and living conditions, using the poor residents who have the ability to work as a main exploit objects, imply the anti-poverty strategies in per household, increase their per capita income.

Third, take measures that suit local circumstances and achieve coordinated development. According to the actual situation in Xinjiang, they should prominent its advantages and features, combining with industrialization, urbanization and agricultural modernization to realize poverty alleviation and rural development, promoting the smooth carry out and development of anti-poverty and other works.

Fourth, reform and innovation, open and leading, which means to emancipate the mind, explore new ideas, innovation poverty alleviation strategies in different regions of Xinjiang, and explore new ways that suitable for actual conditions.

Fifth, government leading and regarding masses as the main body, which means continues to adhere to government's leading role, integrate social forces to participate in poverty alleviation projects, mobilize their activeness and creativity and insist on regarding masses as the main objectives of anti-poverty and development.

\section{Suggestions on the precise poverty alleviation in Xinjiang Uygur Autonomous Region}

\section{Perfect the safeguards of precise poverty alleviation}

In order to ensure the carry out of precise anti-poverty measures, we have to improve the necessary safeguards. First, strengthen the organization and leadership, enhance the cooperation between towns and departments, attend to their own duties and jointly promote the orderly implement of precise anti-poverty. Second, strengthen the propaganda and mobilization at all stages and strengthen its ideological work. Again, fulfill the poverty alleviation funds, integrate of all aspects resources to ensure the fund was in place and documented. Then, strict the supervision in all aspects of anti-poverty work, ensure reach working group was responsible and serious. Finally, strengthen popular participation, fully play their ability to participate in the process and involved in anti-poverty programs, enjoying the rights to learn the truth and enjoyment. Only by perfect these safeguards, can we ensure the smooth development of follow-up anti-poverty works.

\section{Perfect the precise poverty alleviation mechanism}

First, improve the identification mechanism. Identify the poor villages and poor residents is the major operation, therefore we have to improve the mechanism of precise anti-poverty work, 
enhance propaganda and standardize operational procedures to ensure the quality of anti-poverty information, improve supervision and evaluation work according to the method of autonomous sample checking, municipal supervision, county verification and rural carry out. Second, clear the rights. Strictly based on method of regional co-ordination, state responsible and counties to carry out and precisely organize the anti-poverty plan in each poverty villages. According to the poverty alleviation programs instituted by national precise anti-poverty, establish a leading group and inspection group, using area supervision system to act anti-poverty work, clear the job responsibilities and tasks of various departments. Finally, improve the dynamic management mechanism of each poverty residents. In precise anti-poverty, it imply the filing and carding dynamic management mechanism for poor households, improve the mechanism and effectiveness, timely collect and updating filing and carding information, to guarantee the one who need help enjoy corresponding assistance.

\section{Fulfill the implementation of precise poverty alleviation}

First, realize nine supports to village: transport supports, water conservation supports, electric circuit supports, science and technology supports, education supports, health supports, tourism supports, organization supports. Then, improve nine household's supports: training, employment, industrial, finance, transfer, information, propaganda, housing and assistance. Only by this way, can we truly improve and fulfill the precise anti-poverty work, ensure to protect the one who needs help obtain effective poverty alleviation assistance.

\section{Conclusions}

Xinjiang Uygur Autonomous Region is an indispensable part of our country, and we must do a solid work to promote the anti-poverty work in order to promote its development, perfect relative safeguards, establish and improve the poverty alleviation mechanism, combing with industrialization, urbanization and agriculture modernization, connecting with economic growth, agricultural development and other works, to decrease the poverty gap and the gap with national per capita income, to realizing a rapid development.

\section{References}

[1] Wang J, Dong Y. Study on precise poverty alleviation problem in Xinjiang. Decision and Information, 2016(2): 177-178. (In Chinese)

[2] Wang J, Pan Z. Precise poverty alleviation-the application and innovation of anti-poverty in Xinjiang Autonomous Region. Seek Truth from Facts, 2015, 06. (In Chinese)

[3] Xing S. Precise poverty alleviation promotes the prosperity and development of all ethnic groups in Xinjiang. New Silk Road, 2016: (3). (In Chinese)

[4] He L. Sheckleyti Zacher further promote precise poverty alleviation program. China Poverty Alleviation, 2015: (3). (In Chinese)

[5] Fang S. Border anti-poverty is the key to out of poverty for Xinjiang. West Development, 2016(1). (In Chinese)

[6] Han Z. Anti-poverty situation in Xinjiang and developing suggestions. Rural Economy and Science, 2014(8): 196-199. (In Chinese)

[7] Wang X. Reflections on corps precise anti-poverty. Journal of the Party School of XPCC of C.P.C, 2016, 158(1): 5-8. (In Chinese) 